\title{
Feminismo de plataformas: protesta y política de la organización espacial
}

\section{Rianka Singh ${ }^{1}$}

El presente artículo es una traducción² de Singh, R. (2018). Platform Feminism: Protest and the Politics
of Spatial Organization. Ada: A Journal of Gender, New Media, and Technology, No. 14.
10.5399/uo/ada.2018.14.6 Disponible en https://adanewmedia.org/2018/11/issue14-singh/
Cómo citar: Singh, R. (2021). Feminismo de plataformas: protesta y política de la organización espacial.
(Traducción de Carolina Monti, Guillermina Yansen, Emilio Cafassi y Agostina Dolcemáscolo). Revista
Hipertextos, 9(15), 15-23. DOI: https://doi.org/10.24215/23143924e026

Resumen. Este artículo pone en cuestión la utilidad política de las plataformas como medio para la resistencia feminista. A partir de ejemplos como el \#MeToo, y la Marcha de Mujeres en Washington, movimientos que se apoyaron en las plataformas para revitalizar lo que Sarah Banet-Weiser ha denominado "feminismo popular" (2018), argumento que las plataformas mediáticas tienden a asumir determinadas ideas de seguridad, privilegio y poder en relación con el espacio social. Destacando cómo las personas negras, indígenas y de color (BIPOC, en inglés) se organizan en el espacio social, señalo que el foco en la amplificación y la elevación, facilitado por la lógica de la plataforma, vela las necesidades de quienes resisten desde los márgenes. Introduzco las estrategias espaciales utilizadas por quienes deben negociar el espacio de manera distinta para desafiar la centralidad de las plataformas como medio estructurante de las luchas feministas contemporáneas.

Palabras clave: activismos feministas, plataformas de medios, políticas, organización espacial.

\section{Platform Feminism: Protest and the Politics of Spatial Organization}

Abstract. This article brings into question the political utility of platforms as media for feminist resistance. Using examples of \#Me'Too, and the Women's March on Washington, movements that have relied on the platform for reinvigorating what Sarah Banet-Weiser has called "popular feminism” (2018), I argue that common media platforms tend to infer an underlying assumption of safety, privilege and power in relation to social space. Through highlighting how BIPOC people organize in social space, I argue that the focus on amplification and elevation, facilitated by the logics of platform, obscures the needs of those who resist on the margins. I introduce the spatial strategies employed by those who must

\footnotetext{
${ }^{1}$ Rianka Singh es doctoranda en la Facultad de la Información de la Universidad de Toronto, y ha participado de una residencia doctoral en el Centro McLuhan de Cultura y Tecnología. Su investigación doctoral se focaliza en la intersección entre estudios feministas de medios, estudios de plataformas y geografía feminista.

2 Traducción realizada por parte del equipo editorial de Hipertextos: Carolina Monti, Guillermina Yansen, Emilio Cafassi y Agostina Dolcemáscolo.
} 
negotiate space differently to challenge the centrality of platforms as media the structure contemporary feminist protest.

Keywords: feminist activism, media platforms, politics, spatial organization.

\section{Feminismo de plataformas: protestos e política da organização espacial.}

Resumo. Este artigo questiona a utilidade política das plataformas como mídia para a resistência feminista. Usando exemplos de \#MeToo, e da Marcha das Mulheres em Washington, movimentos que confiaram nas plataformas para revigorar o que Sarah Banet-Weiser chamou de "feminismo popular" (2018), eu defendo que plataformas comuns de mídia tendem a inferir uma suposição subjacente de segurança, privilégio e poder em relação ao espaço social. Ao destacar como as pessoas do BIPOC se organizam no espaço social, defendo que o foco na amplificação e elevação, facilitado pela lógica das plataformas, obscurece as necessidades daqueles que resistem nas margens. Apresento as estratégias espaciais empregadas por aqueles que devem negociar o espaço de forma diferente, para desafiar a centralidade das plataformas como mídia a estrutura do protesto feminista contemporâneo.

Palavras-chave: ativismo feminista, plataformas de mídia, política, organização espacial. 
El escenario de la Marcha de Mujeres en 2017 en Washington fue amplio y estuvo cubierto por carteles de vinilo que se podían leer a la distancia. En las grabaciones de las noticias y en las imágenes que circularon por Internet en los días posteriores a la marcha, vemos una plataforma negra, y unos pocos cuerpos sobre ella que se elevan en el centro de un espacio repleto de gorros rosas y carteles de protesta. Las manifestantes se concentran alrededor del escenario. El escenario actúa como ancla para que los cuerpos individuales, y por extensión la multitud, se orienten hacia él. El papel del escenario, la plataforma elevada, ocupa un lugar permanente en las historias y prácticas del activismo feminista. Sin embargo, el discurso contemporáneo en torno a las plataformas y el feminismo no se centra en los escenarios materiales que se han establecido como lugares de articulación de políticas feministas, sino más bien en las plataformas digitales que se han convertido en herramientas importantes para los proyectos feministas. Podríamos pensar en Twitter, blogs y otras aplicaciones digitales como medios para alzar la voz - una tarima digital que amplifica la voz individual. En este artículo, reconsidero las plataformas digitales como lugares para el activismo feminista. Introduzco y cuestiono la plataforma como un medio significativo que estructura la política feminista hoy en día. ¿Cómo podemos empezar a entender las diferentes estrategias espaciales y mediatizadas de las activistas cuyas relaciones con el espacio son más complicadas que la activación de la plataforma y su simbolismo?

Con sus gorros rosas tejidos y su ingeniosa señalización, la Marcha de Mujeres en Washington surgió el año pasado como una gran contra-narrativa simbólica a la administración de Trump. Junto a la Marcha, los hashtags \#Me'Too y \#Timesup son otras expresiones de lo que Sarah Banet Weiser (2018) llama feminismo popular que han dominado el discurso popular en Norteamérica y en otros lugares en los últimos meses. Todos estos recientes eventos de alto perfil han sido objeto de respuestas misóginas. La legitimidad de las denuncias públicas de agresión y acoso sexual ha sido motivo de debate y las protestas han sido ridiculizadas. El periodista Andrew Sullivan incluso llamó a resistir "los excesos del \#Metoo" (2018), tildando al movimiento de mero "pánico sexual". Sin embargo, estos movimientos también han sido denunciados por académicas feministas por reforzar las propias percepciones universalizadoras y esencialistas de las "mujeres" que históricamente han excluido a la mayoría de las mujeres que no son blancas y/o de clase media, trans y queer (Moss y Maddrell, 2017; Willoughby, 2017). Las protestas han sido acusadas de corporativas y neoliberales porque desarticulan la violencia sistemática y parecen ciegas a otras formas de opresión al margen de la experiencia de las mujeres blancas de clase media en el espacio público (Rottenberg, 2017).

Es significativo que cada una de estas recientes movilizaciones feministas se apoye en plataformas de medios digitales como Twitter y Facebook. Estas plataformas de redes sociales contribuyen a que el feminismo sea visible y accesible. La plataforma se ha convertido en sinónimo de redes sociales y aplicaciones móviles en el contexto de la cultura digital (Gillespie, 2010; Hands, 2013; Langlois y Elmer, 2013; Taylor, 2014; Srnicek, 2017) y es esta iteración de la palabra la que se asocia más comúnmente con los movimientos feministas contemporáneos mediatizados. Pero, a veces, estos movimientos también emplean plataformas físicas. Por ejemplo, los escenarios de la Marcha de Mujeres proporcionaron una plataforma a la política feminista a través de celebridades y otras feministas populares. El papel del escenario, la plataforma elevada, ocupa un lugar perdurable dentro de las historias y prácticas del activismo feminista. Los escenarios, los podios, las tarimas y las plataformas digitales son todos medios que amplifican, elevan y hacen visibles los cuerpos. Pero todas estas plataformas mediáticas bastante 
comunes tienden a asumir determinadas ideas de seguridad, privilegio y poder en relación con el espacio social. El enfoque en las plataformas tiende a a opacar las necesidades de quienes no se adaptan tan fácilmente a ellas. Dado que las plataformas elevan sólo algunas voces y regulan la acción, también reproducen necesariamente un determinado tipo de feminismo. Algunas formas de resistencia se consideran aceptables, mientras que otras no. Por ejemplo, las personas más expuestas a los abusos misóginos, racistas y homofóbicos buscan resistir de forma diferente o no son amplificadas por las plataformas. Esto va en contra de la lógica del feminismo interseccional, ya que las formas simultáneas de opresión no tienen la misma importancia en la plataforma. Esto no quiere decir que las herramientas en línea no puedan o no deban utilizarse para proyectos políticos feministas, sino que las plataformas pueden limitar las posibilidades de la política feminista. Al establecer conexiones entre el escenario material de la Marcha de Mujeres en Washington y las plataformas digitales de otras expresiones del feminismo popular contemporáneo, planteo que para que el activismo político feminista sea generativo, es necesario dejar de lado la plataforma.

Abordo la plataforma como un medio significativo para alterar las relaciones políticas y sociales. No me interesa tanto el contenido que se comparte sino la posibilidad de las plataformas como medios que estructuran lo político y que tienen sus propias lógicas. Esta línea de pensamiento se inspira en la obra de McLuhan "El medio es el mensaje" (1964) y, más recientemente, en el trabajo de los teóricos de los medios de comunicación que destacan las formas en que los medios estructuran lo social y lo político y, al hacerlo, amplían lo que podríamos entender como medios de comunicación en primer lugar (Sharma, 2008; Brock, 2012; Packer y Wiley, 2012; McPherson, 2014; Feigenbaum, 2014). Anna Feigenbaum (2014), por ejemplo, sugiere en su artículo sobre los medios de comunicación de Occupy que "cuando los objetos y las arquitecturas se encuentran repetidamente en los lugares de lucha, se vuelven más y más pegajosos, cargados de significado y potentes en sentimientos" (p. 17). La plataforma como medio que aparece una y otra vez en los lugares de lucha feminista es un objeto cargado de valores potentes y su relación con el feminismo requiere una exploración con múltiples matices.

Para quienes experimentan la vida desde lainterseccionalidad, muchas de las cuales son mujeres y negras, marrones, queer, trans y discapacitadas, el espacio debe negociarse de manera diferente. Las estrategias espaciales de los cuerpos marginados incluyen métodos cotidianos de negociación del espacio y movimiento por el mundo. Esto podría incluir cosas como viajar en grupos, elegir caminar por las calles solo en momentos específicos del día, organizar protestas en lugares próximos a ubicaciones particulares, como estaciones de policía u hospitales, o practicar el cuidado personal. Otro ejemplo puede encontrarse en The Winter We Danced (2014), donde el Colectivo Kino-nda-niimi reúne escritos del movimiento Idle No More que se centra en la práctica indígena de invadir los centros comerciales norteamericanos para realizar bailes en ronda como un acto de resistencia. La práctica de la danza circular como resistencia también puede leerse como una estrategia espacial diferencial. Estas estrategias se desarrollan tanto como forma de lidiar con las reglas institucionales de espacios particulares, como forma de supervivencia. Para algunos, las estrategias espaciales diferenciales que surgen se centran en factores como la seguridad, la evasión, el encubrimiento y el cuidado por sobre el factor de amplificación y popularización de los movimientos de resistencia. Pero este enfoque en las estrategias y la supervivencia no es antitético a la organización de protestas o la toma culminante del Estado. La necesidad de reconfigurar constantemente las formas de convocatoria debe interpretarse como prácticas significativas de resistencia política. 
En 2016, por ejemplo, miembros del movimiento Black Lives Matter acamparon fuera de la sede de la policía de Toronto durante dos semanas en protesta por los disparos de la policía a Andrew Loku. Para aquellos que acamparon, el espacio se convirtió en uno de "sanación y construcción de comunidades", según la cofundadora de BLMTO ${ }^{3}$, Alexandria Williams. A diferencia del enfoque en la visibilidad, o lo que Sarah Banet-Weiser (2018) ha llamado "feminismo afirmativo" que se ha vuelto característico de movimientos populares como la Marcha de Mujeres o el \#Metoo, todo ello posibilitado por diversas plataformas, estas otras consideraciones espaciales dan cuenta de las preocupaciones críticas de las mujeres de color, queer, trans y / o discapacitadas. La plataforma es una forma de medio culturalmente dominante que es limitada en su capacidad para registrar y dar cuenta de las formas feministas interseccionales de resistencia y rechazo. En otras palabras, la plataforma material de protestas y marchas es con bastante frecuencia un medio que se rechaza. Lo que podríamos considerar descubrir y ampliar, en cambio, son las estrategias espaciales diferenciales que emplean las activistas feministas marginadas.

Figura $\mathbf{n}^{\mathbf{0}}$ 1: Manifestantes bailando en las carpas de Back Lives Matter, cuartel de policía de

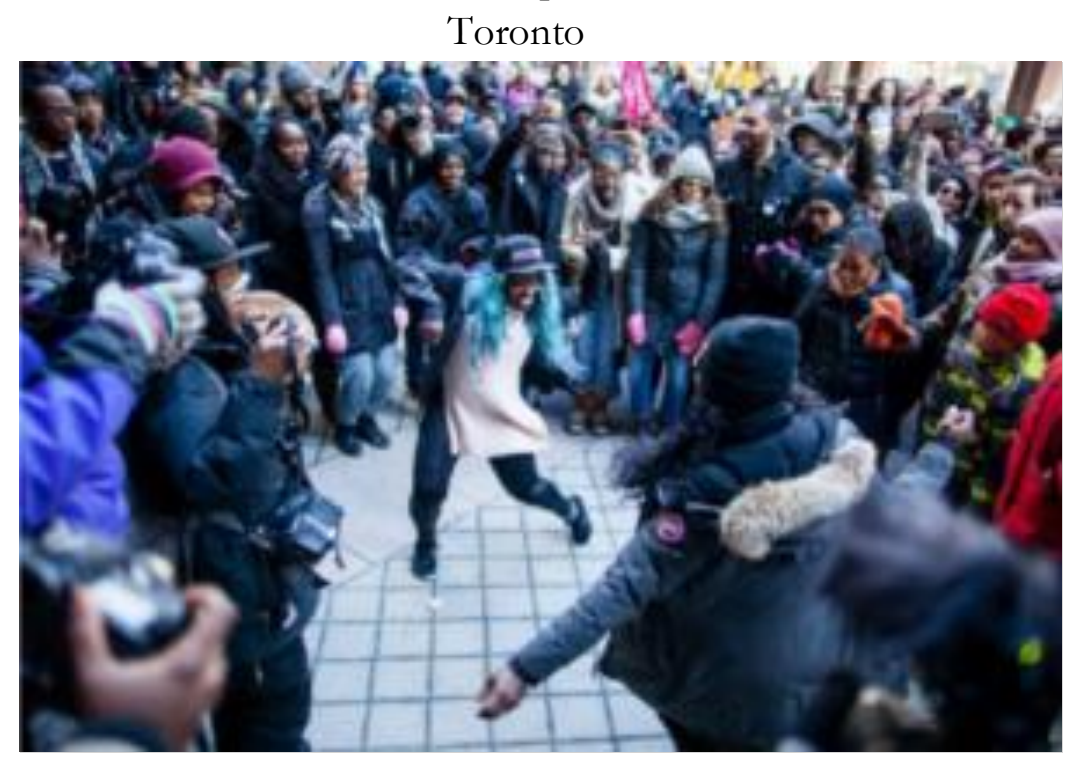

Fuente: Toronto Star, 3 de abril de 2016.

Una estrategia espacial similar al activismo fuera de línea y sitios de protesta se reproduce en el activismo feminista en línea. Las plataformas digitales son aplicaciones en línea, definidas por Nick Srnicek como "negocios que proporcionan las bases de hardware y software para que otros operen” (2017, p.6). Las plataformas de redes sociales como Facebook y Twitter han sido incorporadas al activismo digital a través de importantes movimientos internacionales como la Primavera Árabe y Occupy Wall Street, donde los sitios en línea se utilizaron para organizar y construir nuevas formas de colectividad (Gerbaudo, 2012; Bennett y Segerberg, 2013; Milán, 2013; Pappacharisi, 2014). La relación del feminismo con la plataforma es evidente a través de las formas en que los sitios de redes sociales, como Twitter, o actividades como los blogs, son a menudo consideradas -especialmente en el discurso popular-, como revitalizantes e impulsoras del feminismo contemporáneo. A pesar de la preocupación del discurso popular por el

\footnotetext{
${ }^{3}$ [Notas de les traductores] La autora se refiere aquí al movimiento "Black Lives Matter- Toronto".
} 
feminismo habilitado por plataformas, que lo hace parecer particularmente actual, la plataforma ha sido una herramienta feminista en varias formas desde al menos principios de 1900. Las plataformas en línea son herramientas y sitios importantes para la protesta feminista porque dan vOz a aquellos que históricamente han sido excluidos o borrados del discurso público y también porque pueden utilizarse como herramientas de organización (Baer, 2016; Keller, 2012; Rentschler, 2015). Sin embargo, los académicos que se dedican al trabajo sobre el feminismo interseccional problematizan la promesa democrática de las plataformas digitales al argumentar que las plataformas defienden y recrean las estructuras existentes de misoginia, racismo y capacitismo en el siglo XXI (Noble y Tynes, 2016). Al igual que el escenario material que reproduce un tipo particular de feminismo, amplificando solo algunas voces, así también lo hacen las plataformas digitales. Jessie Daniels' (2016), en su destacado artículo 'El problema con el feminismo blanco: blancura, feminismo digital e Internet interseccional", plantea el argumento de que, en los estudios sobre el feminismo digital, está subteorizado el "dominio de las mujeres blancas como arquitectas y defensoras de un marco particular del feminismo en la era digital" (p. 42). Daniels postula que las formas en que el feminismo en línea se articula a menudo en la cultura popular es a través de una lente feminista blanca y nos pide que analicemos cómo "el feminismo blanco se ha beneficiado de este desarrollo tecnológico" (p. 56). Daniels sugiere que debido a que las mujeres blancas son las arquitectas del feminismo digital, el privilegio blanco está embebido en estos sistemas, lo que limita su accesibilidad y utilidad para las personas de color y otras poblaciones minorizadas.

Vale la pena situar este argumento sobre las plataformas dentro de los estudios contemporáneos sobre los medios de comunicación y, en particular, en el campo de estudio emergente relacionado con las plataformas digitales y su política. En los últimos años, los estudiosos de los medios de comunicación han centrado su atención en las plataformas. MIT Press tiene una serie completa sobre estudios de plataformas y en 2013 la revista Culture Machine publicó un número sobre "políticas de plataformas". Incluir la palabra "plataforma" en la convocatoria de una conferencia seguramente dará lugar a un buen número de candidatos interesantes. Todo esto para decir que el auge de la plataforma como objeto de estudio ha sido rápido, $\mathrm{y}$, como resultado, la plataforma como sitio de estudio ha pasado desapercibida de manera particular. Específicamente, aún no se ha desarrollado una lectura materialista de las plataformas desde una perspectiva feminista. Los enfoques predominantes se pueden clasificar en trabajos que encajan perfectamente en lo que se ha dado en llamar "estudios sobre plataformas", estudios sobre activismo digital y enfoques feministas de las plataformas. En estos enfoques, se plantean pocas preguntas sobre si la plataforma está haciendo realmente un trabajo productivo para el feminismo; en su lugar, se asume su utilidad o necesidad política. Cuestionar la plataforma y su papel en la resistencia feminista es también desestabilizar una comprensión de la resistencia digital feminista que no funciona como debería para las feministas en los márgenes. El discurso contemporáneo predominante sobre "las plataformas" en los estudios de plataformas no se centra en las etapas materiales y otras superficies elevadas en el espacio físico, sino más bien en las plataformas digitales. Las plataformas se han convertido en sinónimo de redes sociales y aplicaciones móviles en el contexto de la cultura digital (Gillespie, 2010; Hands, 2013; Langlois y Elmer, 2013; Taylor, 2014; Srnicek, 2017). Aquellos que abordan el trabajo de plataforma (Graham, 2017), el capitalismo de plataformas (Srnicek, 2017) y la política de plataformas (Hands, 2013) argumentarán que las plataformas informáticas dan forma, restringen, apoyan o niegan interacciones sociales y políticas importantes a través de estudios de la llamada 
'gig economy ${ }^{14}$.Existe un importante cuerpo académico que ha establecido que las plataformas digitales no son medios neutrales. En cambio, se entiende que las plataformas están imbuidas de jerarquías de poder en las que la información se distribuye de manera desigual con efectos diferenciales (Gillespie, 2010). En algunos casos, las "plataformas" se posicionan y discuten como infraestructuras digitales que unen a grupos de personas y permiten transacciones financieras (Hands, 2013; Srnicek, 2017). Se han establecido algunas conexiones entre plataformas de materiales como superficies elevadas y lugares físicos situados, y plataformas digitales en los campos de estudios de software y estudios de medios y comunicación (Bratton, 2016, Gillespie, 2010). En "The Stack: On Software and Sovereignty", Benjamin H. Bratton ofrece la etimología de la palabra plataforma, proporcionando tres connotaciones: "plataforma como plan de acción, como escenario para un plan y como propuesta de reglas de gobierno" (2016, p. 43). Los estudios de plataformas como un nuevo campo han sido importantes tanto para nombrar como para establecer los nuevos conjuntos de relaciones que permiten las infraestructuras informáticas y diversas aplicaciones móviles. Esta área de estudio emergente también ha abordado la resistencia llevada a cabo -en y a través- de las plataformas digitales al enfocarse específicamente en el trabajo y la gig economy. Pero hay mucho trabajo por hacer en el campo de los estudios de plataformas, especialmente porque faltan en gran medida las perspectivas feministas, queer y de personas de color. Los estudios exhaustivos de la plataforma deben cuestionar la suposición de que solo se puede teorizar la resistencia cuando éstas se abordan como espacios de determinados tipos de trabajo. Además, es importante centrar nuestras preguntas menos en las posibilidades tecnológicas de las plataformas y más en las personas que las utilizan. Aquí es importante el trabajo de los teóricos de los medios interseccionales y materialistas que buscan visibilizar cuerpos y voces diferenciadas que operan en plataformas digitales (Hedge, 2011; Gajalla, 2012; McPherson, 2014). André Brock (2012) por ejemplo, en su trabajo en Black Twitter problematiza "la investigación de las ciencias sociales y la comunicación que intenta preservar una perspectiva daltónica de los esfuerzos en línea al normalizar la blancura y la diferencia de todos los demás" (p. 546). Este cambio de pensamiento podría ayudar a desarrollar un modelo de la diferencia, en lugar de cosificar las estructuras de poder existentes.

Cuando las plataformas en línea aparecen en la investigación feminista en los estudios sobre medios y comunicación, es a través de los debates sobre las posibilidades políticas que permiten los medios digitales (Keller, 2012; Rentschler, 2015; Baer, 2016). En su artículo "Redoing Feminism: Digital Activism, Body Politics and Neoliberalism" Hester Baer (2016), comentando el feminismo de los hashtags, postula que "Al proporcionar una plataforma crítica para tales discusiones, las campañas feministas de Twitter literalmente 'rehacen el feminismo'” (p. 29). Este trabajo, aunque es importante para resaltar cómo algunas activistas feministas han utilizado las plataformas digitales para la resistencia, parece asumir una vinculación particular con las plataformas. Si no se piensa en la plataforma desde una perspectiva materialista, cosa que no hace la literatura existente, es difícil pensar en los feminismos digitales más allá de las lógicas de las plataformas.

Al intervenir en estos campos, al plantear preguntas sobre la plataforma y su papel en la estructuración de la lucha feminista interseccional, podría ser posible descubrir, o al menos

4 [Nota de les traductores] Este este término podría ser traducido como "economía informal", aunque una definición más acertada sería "economía de trabajos temporarios o precarios". 
resaltar, las formas importantes en que las mujeres que también son personas de color, queer, trans y/o discapacitadas, se desarrollan. Estrategias espaciales diferenciales en momentos de resistencia. Necesitamos comenzar a pensar en cómo la lucha feminista ha estado ligada a varias iteraciones de la plataforma y, por extensión, a las organizaciones espaciales normativas y cómo estos arreglos se renegocian constantemente.

\section{Referencias}

Baer, H. (2010). Redoing Feminism: Digital Activism, Body Politics, and Neoliberalism. Feminist Media Studies 16.1, p.17-34.

Banet-Weiser, S. (2018). Popular Feminism: \#metoo. LA Book of Reviews.

Battersby, S. J. (2016, 2 de abril). Inside Toronto's Black Lives Matter Camp. The Toronto Star, https://www.thestar.com/news/gta/2016/04/03/inside-torontos-blacklives-mattercamp.Html

Bratton, B. H. (2015). The Stack: on Software and Sovereignty. MIT Press.

Brock, A. (2012). From the Blackhand Side: Twitter as a Cultural Conversation. Journal of Broadcasting and Electronic Media, 56:4, p.529-549.

Daniels, J. (2015). The Trouble with White Feminism: Whiteness, Digital Feminism and the Intersectional Internet, En Noble, S.U. and Tynes, B.M (eds), The Intersectional Internet: Race, Sex, Class and Culture Online. New York: Peter Lang Publishing.

Feigennbaum, A. (2014). Resistance Matters: Tents, Tear Gas and the 'Other Media' of Occupy. Communication and Critical/ Cultural Studies. 11-1, p.15-24.

Gajalla, R. (2012). Cyberculture and the Subaltern: Weavings of the Virtual and Real. Lexington Press. Hands, J. (2013). Platform Communism. Culture Machine, 14, p. 1-24.

Hedge, R. S. (2011). Circuits of Visibility: Gender and Transnational Media Cultures. NYU Press.

Keller, J. (2012). Virtual Feminisms. Information, Communication \& Society 15.3, p.429-47.

Kino-nda-niimi Collective (2104). The Winter We Danced: Voices from the Past, the Future, and the Idle No More Movement. Manitoba: ARP Books.

Langois, G. y Elmer, G. (2013). The Research Politics of Social Media Platforms. Culture Machine. Vol.14, p.1-17.

McLuhan, M. (1964). Understanding media. London: Sphere Books.

McPherson, T. (2014). Designing for Difference. Differences: A Journal of Feminist Cultural Studies, 25:1, p. $177-188$.

Moss, P. y Maddrell, A. (2017). Emergent and divergent spaces in the Women's March: the challenges of intersectionality and inclusion. Gender, Place \& Culture, 24:5.

Noble, S. U. y Tynes, B. M. (2015). The Intersectional Internet: Race, Sex, Class and Culture Online. New York: Peter Lang Publishing.

Packer, J. y Crofts Wiley, S. B. (2012). Communiction Matters: Materialist Approaches to Media, Mobility and Networks. Routledge.

Puar, J. (2015). Queer Times, Queer Assemblages. Social Text, 23, p.121-139.

Puar, J. (2011). 'I would rather be a cyborg than a goddess' Intersectionality, Assemblage, and Affective Politics. European Institute for Progressive Cultural Policies (Transversal: inventions).

Rentschler, C. (2015). \#Safetytipsforladies: Feminist Twitter Takedowns of Victim Blaming. Feminist Media Studies 15.2, pp. 353-356. 
Rottenberg, C. (2013, 13 de diciembre). Can \#MeToo Go Beyond White Neoliberalism? Aljazeera http://www.aljazeera.com/indepth/opinion/metoo-whiteneoliberal-feminism-171213064156855.html

Sharma, S. (2008). Taxis as Media: A Temporal Materialist Reading of the Taxicab. Social Identities: Journal of Race, Nation, and Culture, 14.4, p.457-464.

Srnicek, N. (2016). Platform Capitalism. Cambridge: Polity.

Sullivan, A. (2018, 12 de enero). It's Time to Resist the Excesses of \#Me'Too. NY Mag. http:/ / nymag.com/daily/intelligencer/2018/01/andrew-sullivan-time-to-resist-excesses-ofmetoo.html

Taylor, A. (2014). The People's Platform: Taking Back Power and Culture in the Digital Age. New York: Metropolitan Books.

Willoughby, V. (2017, 23 de enero). Signs At the Women's March on Washington Called out White Feminism. Teen Vogue, https://www.teenvogue.com/story/signs-at-the-womensmarch-on-washington-called-out-white-feminism 